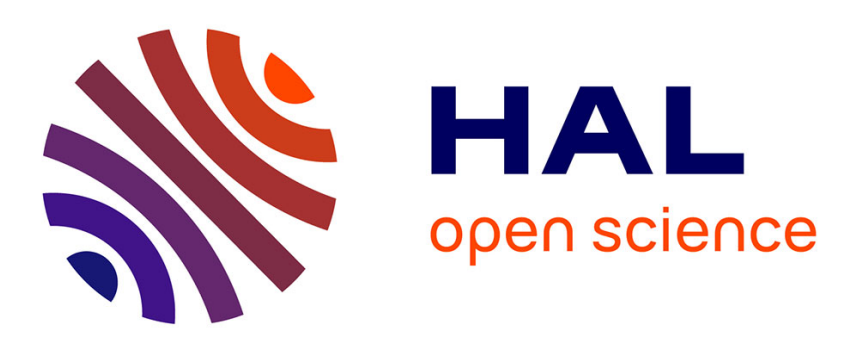

\title{
Thermal effects accompanying the deformation of natural rubber
}

Jose Ricardo Samaca Martinez, Jean-Benoit Le Cam, Xavier Balandraud, Evelyne Toussaint, Julien Caillard

\section{- To cite this version:}

Jose Ricardo Samaca Martinez, Jean-Benoit Le Cam, Xavier Balandraud, Evelyne Toussaint, Julien Caillard. Thermal effects accompanying the deformation of natural rubber. European Conference on Constitutive Models for Rubber VIII, Jun 2013, San Sebastian, Spain. hal-01136538

\section{HAL Id: hal-01136538 \\ https://hal.science/hal-01136538}

Submitted on 18 May 2020

HAL is a multi-disciplinary open access archive for the deposit and dissemination of scientific research documents, whether they are published or not. The documents may come from teaching and research institutions in France or abroad, or from public or private research centers.
L'archive ouverte pluridisciplinaire HAL, est destinée au dépôt et à la diffusion de documents scientifiques de niveau recherche, publiés ou non, émanant des établissements d'enseignement et de recherche français ou étrangers, des laboratoires publics ou privés. 


\title{
Thermal effects accompanying the deformation of natural rubber
}

\author{
J.R. Samaca Martinez \\ Clermont Université, Université Blaise Pascal, Institut Français de Mécanique Avancée, Institut Pascal, \\ Clermont-Ferrand, France \\ CNRS, UMR 6602, Université Blaise Pascal, Institut Pascal, Aubière, France \\ Manufacture Française de Pneumatiques Michelin, CERL Ladoux, Clermont-Ferrand, France
}

J.-B. Le Cam

Université De Rennes 1, Larmaur ERL CNRS 6274, Campus de Beaulieu, Rennes, France

X. Balandraud \& E. Toussaint

Clermont Université, Université Blaise Pascal, Institut Français de Mécanique Avancée,

Institut Pascal, Clermont-Ferrand, France

CNRS, UMR 6602, Université Blaise Pascal, Institut Pascal, Aubière, France

J. Caillard

Manufacture Française de Pneumatiques Michelin, CERL Ladoux, Clermont-Ferrand, France

\begin{abstract}
This paper deals with the thermal effects associated with deformation processes in unfilled natural rubber. Temperature variations are measured by infrared thermography during cyclic uniaxial mechanical tests at ambient temperature. Results show that natural rubber mainly exhibits entropic behaviour: the material produces (resp. absorbs) heat during loading (resp. unloading). The thermal responses obtained provide complementary information regarding the mechanical analysis of changes in the microstructure, especially strain-induced crystallization. The crystallization of the polymer chains under tension leads to a temperature increase of the order of several degrees Celsius. If crystallization occurs, a hysteresis loop is observed in terms of the strain-stress relationship. Moreover, stress relaxation tests show that the thermal signatures of crystallization and of crystallite melting are different. Indeed, if the strain is maintained fixed during loading, the temperature continues to increase for a few seconds before returning to the ambient temperature. This reveals that crystallization continues during relaxation. On the contrary, if the strain is maintained fixed during unloading, the specimen seems to return instantaneously to the ambient temperature. Throughout this paper, the effect of heat exchanges with the outside of the specimen (non-adiabaticity) on the temperature variations is taken into account for the analysis.
\end{abstract}

\section{INTRODUCTION}

It is well-known that Natural Rubber (NR) has excellent mechanical properties (i.e. high elasticity, high damping, high elongation at failure, etc) which are widely used in many fields, such as mechanical, automotive and aerospace engineering. However, this type of material is subjected to numerous physical mechanisms during the deformation process which are still not clearly understood and feed the scientific debate: Mullins effect (Mullins 1948, Chagnon, Verron, Gornet, Marckmann, \& Charrier 2004), cavitation (Stringfellow \& Abeyaratne 1989, Le Cam \& Toussaint 2008), strain induced crystallization
(Toki, Fujimaki, \& Okuyama 2000, Toki, Sics, Ran, Liu, Hsiao, Murakami, Senoo, \& Kohjiya 2002, Trabelsi, Albouy, \& Rault 2002, Huneau 2011) and energetic and entropic effects on the thermomechanical response. From an experimental point of view several techniques have been used to study such phenomena, X-ray diffraction, X-ray microtomography, dilatometry, among others. Nevertheless, no temperature variation or heat production can be detected with the abovementioned techniques.

Full-field measurement techniques and especially, Infrared (IR) thermography are appropriate techniques to detect the heat sources produced by the material itself during the deformation 
process from measured temperature variations. This technique has been widely applied to metals, polymers and composite materials (see for instance (Chrysochoos \& Louche 2000, Chrysochoos \& Louche 2001)), but rarely to elastomeric materials (Pottier, Moutrille, Le Cam, Balandraud, \& Grédiac 2009, Toussaint, Balandraud, Le Cam, \& Grédiac 2012). In this work we are mainly interested in the analysis of the temperature variations obtained by IR thermography during the deformation processes of unfilled natural rubber, in order to characterize the thermal response of such crystallizable rubber under homogeneous cyclic uniaxial tensile test, at ambient temperature.

In Section 2 we present the experimental setup, i.e. the material, the specimen geometry, the loading conditions and the measurement device.

In Section 3 we give the results obtained for cyclic and relaxation tests by associating mechanical and thermal responses.

Finally, a conclusion recalls the main results of the paper and presents the perspectives.

\section{EXPERIMENTS}

\subsection{Material and specimen geometry}

The material considered here is an unfilled natural rubber NR (supplied by Michelin Co). Its material formulation is given in Table 1. This material was chosen in order to analyze the thermal response of the macromolecular network without interaction between the rubber matrix and the fillers. Though, this kind of materials is subject to StrainInduced Crystallization (SIC in the following) and it is relevant to identify the thermal response of such phenomenon.

In NR, the crystallization of the polymer chains is observed in uniaxial tension starting from a stretch ratio, defined as the ratio between current length and the initial length, of about $\lambda=4$. During unloading, crystallite melting should be complete at a lower stretch ratio, typically equal

Table 1. Chemical composition in parts per hundred rubber (phr).

\begin{tabular}{lc}
\hline Ingredient & Quantity \\
\hline Natural rubber NR & 100 \\
Carbon black & 0 \\
Antioxidant 6PPD & 1.9 \\
Stearic acid & 2 \\
Zinc oxide ZnO & 2.5 \\
Accelerator CBS & 1.6 \\
Sulfur solution 2H & 1.6 \\
\hline
\end{tabular}

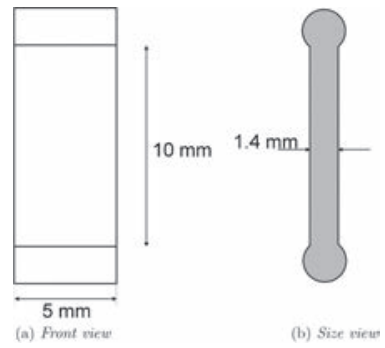

Figure 1. Specimen geometry.

to about $\lambda=3$ (Toki, Fujimaki, \& Okuyama 2000, Trabelsi, Albouy, \& Rault 2003, Le Cam \& Toussaint 2008). In the following, these stretch ratios at which crystallization begins and at which crystallite melting is complete are denoted $\lambda_{c}$ and $\lambda_{m}$, respectively.

The sample geometry is presented in Figure 1. It is a typical dumbbell form sample, with a $5 \mathrm{~mm}$ width, $10 \mathrm{~mm}$ height and $1.4 \mathrm{~mm}$ thickness. Its width was chosen to ensure that the strain and stress fields are as homogeneous as possible, thus corresponding to a uniaxial tension test state.

\subsection{Loading conditions}

Mechanical loadings were applied using a $50 \mathrm{~N}$ INSTRON 5543 testing machine. Two types of tests were carried out under imposed displacement at a constant loading rate $\pm 300 \mathrm{~mm} / \mathrm{min}$ :

1. the first test corresponds to four sets of three cycles, for four increasing maximum stretch ratios: $\lambda_{1}=2, \lambda_{2}=5, \lambda_{3}=6$ and $\lambda_{4}=7.5$ (see Fig. 2(a)). $\lambda_{1}$ was chosen inferior to $\lambda_{c}, \lambda_{2}$ was close to $\lambda_{c}$ and $\lambda_{3}$ and $\lambda_{4}$ are superior to $\lambda_{c}\left(\lambda_{4}\right.$ is close to the failure stretch ratio). The signal shape was chosen triangular, to ensure a constant strain rate during loading and unloading.

2. the second test consists of applying only one mechanical cycle, including pauses of $30 s$ at the stretch ratios used for the first type of test, i.e. $\lambda_{i}$ for $i=1 \ldots 4$, during both loading and unloading (see Fig. 2(b)).

\subsection{Temperature field measurements}

Temperature measurements were performed using a Cedip Jade III-MWIR infrared camera. The principal features of this camera are presented in Table 2.

The calibration of the camera detectors was performed using a black body and using a NonUniformity Correction (NUC) procedure. In order to ensure that the internal temperature of the camera 


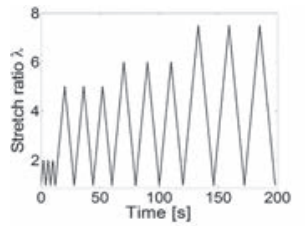

(a) Cyclic test

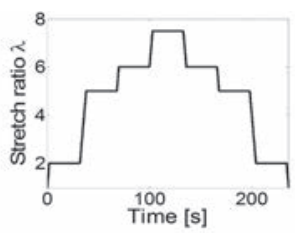

(b) Loading-unloading test with relaxation steps
Figure 2. The two mechanical loading conditions.

Table 2. IR camera features.

\begin{tabular}{ll}
\hline Features & Values \\
\hline Thermal resolution $\left(\left[5-40{ }^{\circ} \mathrm{C}\right]\right)$ & $20 \mathrm{mK}$ \\
Local plane array & $320 \times 240$ pixels \\
Wavelength range & $3.5-5 \mu \mathrm{m}$ \\
Integration time & $1500 \mu \mathrm{s}$ \\
Acquisition frequency & $147 \mathrm{~Hz}$ \\
\hline
\end{tabular}

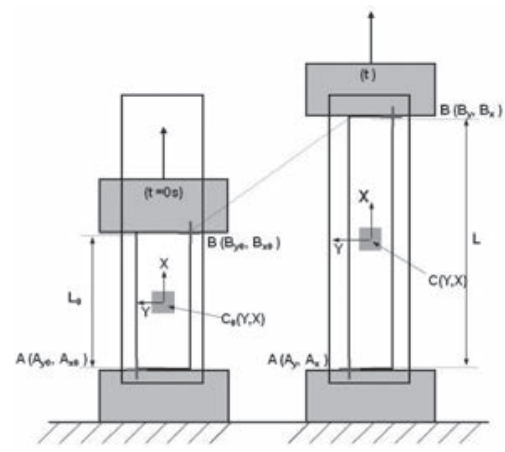

Figure 3. Motion compensation illustration.

was stabilized before performing the calibration and the measurement, it was switched on four hours before the beginning of the experiments. The stabilization of the internal temperature of the camera is necessary to avoid any measurement drift during the tests.

The temperature fields obtained were filtered using an averaging filter. In the present case, the specimen response is considered as thermally homogeneous, due to the very low thermal conductivity of rubber. So, the thermal quantity considered here, is the mean temperature variation of a small zone $(5 p x \times 5 p x$ square located at the middle of the gauge length) during the test (see Fig. 3). This quantity is obtained by subtracting the initial temperature from the current one, after applying a suitable movement compensation technique, for further information see (Samaca Martinez, Le Cam, Balandraud, Toussaint, \& Caillard 2013). As illustrated in Figure 3, the movement of this zone is taken into account in order to associate a temperature with the material zone at any time of the test. The displacement of the moving grip is directly measured from the thermal images.

\section{RESULTS AND DISCUSSION}

\subsection{Cyclic test}

\subsubsection{Mechanical response}

Results obtained at $\pm 300 \mathrm{~mm} / \mathrm{min}$ is presented in Figure 4. This figure presents the nominal stress, defined as the force per initial surface ratio, versus the stretch ratio. Firstly, it can be observed that the mechanical cycles have no effect on the mechanical response, in the sense that no stress softening is observed between cycles.

In order to detail more precisely each mechanical cycle, Figures 5 (a),(b), (c) and (d) give the curves for $\lambda_{1}=2, \lambda_{2}=5, \lambda_{3}=6$ and $\lambda_{4}=7.5$, respectively. Each case exhibits a specific response:

i. for cycles at $\lambda_{1}=2$ and $\lambda_{2}=5$ : In these cases, for both maximum stretch ration tested, no hysteresis loop can be observed.

ii. for cycles at $\lambda_{3}=6$ : A hysteresis loop is formed. The stress difference tends to disappear for a stretch ratio equal to 3 . These results are in good agreement with those reported in the literature for unfilled natural rubber. The hysteresis loop is explained by the difference in the kinetics of crystallization and crystallite melting (Toki, Fujimaki, \& Okuyama 2000, Trabelsi, Albouy, \& Rault 2003, Le Cam \& Toussaint

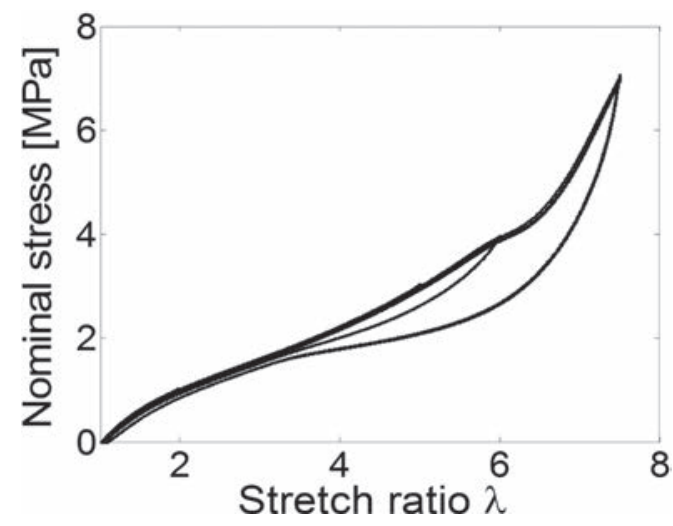

Figure 4. Mechanical response at $\pm 300 \mathrm{~mm} / \mathrm{min}$. 


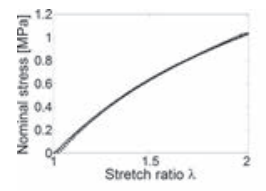

(a) $\lambda_{1}=2$

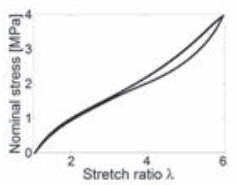

(c) $\lambda_{3}=6$

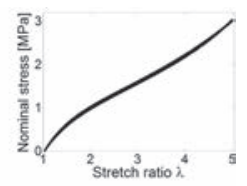

(b) $\lambda_{2}=5$

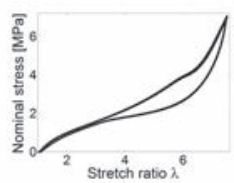

(d) $\lambda_{4}=7.5$
Figure 5. Three mechanical cycles at four increasing stretch ratios.

2008). If the stretch ratio applied exceeds the stretch ratio at which crystallization occurs (around 4 for natural rubber), a hysteresis loop begins to form.

iii. for cycles at $\lambda_{4}=7.5$ : A plateau is observed from $\lambda=6$ on, followed by a high stress increase. As explained in (Toki, Fujimaki, \& Okuyama 2000) and (Trabelsi, Albouy, \& Rault 2003), once SIC occurs, relaxation is induced in the amorphous phase. As a consequence, a plateau forms. For higher stretch ratio levels, crystallites act as fillers and strongly reinforce the material stiffness, which explains the high increase in the nominal stress. As for the previous cycles at $\lambda_{3}=6$, the hysteresis loop closes at around $\lambda=3$, which is close to the stretch ratio at which crystallite melting is assumed to be complete.

\subsubsection{Thermal response}

The thermal response of the specimen was measured during the mechanical test. The aim of such a measurement is twofold. The first objective is to characterize the thermal response of rubber during a classic mechanical test. The second objective is to highlight the effects of the number of cycles on the thermal response.

In order to understand this thermal response, the contribution of the heat exchanges with the outside of the specimen (level of non-adiabaticity of the evolution) must be taken into account. Results are detailed and commented in the following paragraph for each loading step:

i. for cycles at $\lambda_{1}=2$ : Figure 6 (a) gives the temperature variation for the three cycles at $\pm 300 \mathrm{~mm} / \mathrm{min}$. It can be noted that in this figure, the time scale has been initialized at the beginning of each cycle. During the loading phase, the temperature variation first decreases before increasing. This is a well-known phenomenon in rubbery materials (Joule 1857), which is explained by the competition between the effects of internal energy variation and entropy variation with respect to the strain level. This leads to the occurrence of the so-called thermoelastic inversion, in this case close to $\lambda=1.1$. Obviously, this phenomenon is also observed during unloading. It can be also noted that the temperature variation at the end of the first cycle is inferior to that at the beginning of the cycle so a shift in the curve position is observed between the cycles. This observation can easily be explained by considering the heat exchanges with the outside of the specimen (mainly the ambient air), more precisely the effects of the non-adiabaticity conditions on the thermal response. The interested reader is referred to (Samaca Martinez, Le Cam, Balandraud, Toussaint, \& Caillard 2013) for further information.

ii. for cycles at $\lambda_{2}=5$ : Figure 6(a) presents the temperature variations obtained for the second set of three cycles. As in the previous case, the time scale has been initialized at the beginning of each cycle. Two comments can be made from this figure. First, the maximum temperature variation is greater than previously (about $1.8^{\circ} \mathrm{C}$, to be compared to $0.15^{\circ} \mathrm{C}$, see Figure $6(\mathrm{a})$ ). Second, the stabilized regime is not reached after three cycles (different temperatures at the beginning and at the end of the third cycle). This is explained by the fact that the material did not have enough time to reach the stabilized regime. Consequently, stabilization occurs with a greater number of cycles.

iii. for cycles at $\lambda_{3}=6$ : Figure 6(c) presents the temperature variation obtained for the third set of three cycles. This curve exhibits some major dif-

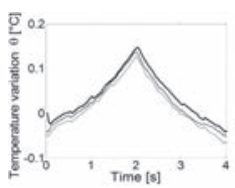

(a) $\lambda_{1}=2$

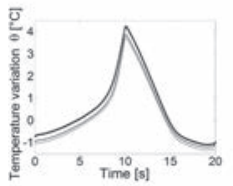

(c) $\lambda_{3}=6$

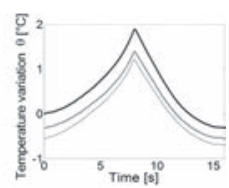

(b) $\lambda_{2}=5$

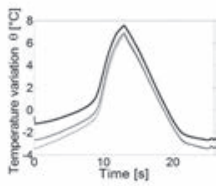

(d) $\lambda_{4}=7.5$
Figure 6. Temperature variations obtained for the four sets of three cycles. 
ferences compared to those obtained for smaller maximum stretch ratios $\left(\lambda_{1}\right.$ and $\left.\lambda_{2}\right)$. This figure shows a great increase in temperature variation of around $3{ }^{\circ} \mathrm{C}$ during loading at time $t=8 \mathrm{~s}$. Two reasons can explain that this phenomenon is due to crystallization. First, crystallization is a strong exothermic phenomenon. Second, the stretch ratio at time $t=7 \mathrm{~s}$ is close to the stretch ratio usually considered for the beginning of crystallization.

iv. for cycles at $\lambda_{4}=7.5$ : Figure $6(\mathrm{~d})$ presents the temperature variation obtained for the fourth set of three cycles. The great increase in temperature is once more observed starting from a stretch ratio close to the value usually considered for the beginning of crystallization. It can also be observed that the temperature rate slightly decreases at the end of each loading phase. Two factors may explain this phenomenon: either heat exchanges with the outside of the specimen, or a decrease in the crystallization rate, as shown in (Flory 1947). Only an analysis based on heat source calculation can provide the explanation. It appears that the stabilized regime is nearly obtained from the second cycle (the second and third unloading curves are superimposed). It should finally be noted that the temperature variation for this maximum stretch ratio applied reaches $9^{\circ} \mathrm{C}$.

\subsection{Loading-unloading test with pauses}

\subsubsection{Mechanical response}

Figure 7 shows that during the loading pauses, the stress relaxes if the stretch ratio applied is higher than $\lambda_{c}$. Upon unloading, the stress does not significantly evolve, whatever the fixed strain. The fact that stress relaxation is observed only if the stretch ratio is superior to that at which crystallization begins is in good agreement with the results obtained by (Marchal 2006) and (Le Cam \& Toussaint 2008). Moreover, the fact that no significant evolution in stress is observed during

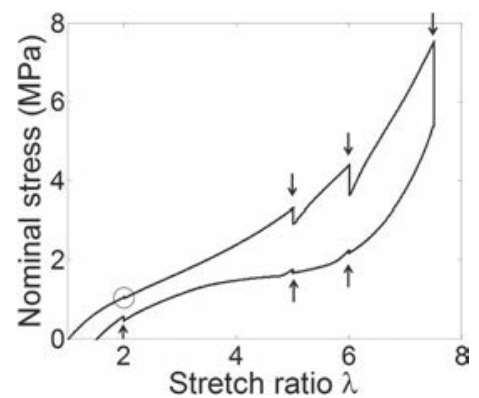

Figure 7. Nominal stress versus stretch ratio during the relaxation test. unloading seems to highlight a difference in the kinetics of crystallization and crystallite melting. Finally, the residual stretch ratio obtained at the end of the mechanical cycle is nearly equal to 1.5. This value is much higher than that obtained during the cyclic test (1.1, see Fig. 4). Two hypotheses can be proposed to explain such a result. First, the static relaxations imply additional crystallization, leading to more crystals which are not completely melted at the end of the procedure. Second, there are internal stresses due to entanglements in the material network (topological stresses) whose effect is altered by the successive relaxation steps.

\subsubsection{Thermal response}

The thermal measurements performed during the test provide complementary information about the processes of crystallization and crystallite melting.

Figure 8 presents the temperature variation $\theta$ versus time. The value of $\theta$ varies between $-6^{\circ} \mathrm{C}$ and $4^{\circ} \mathrm{C}$. Let us now examine this temperature evolution in two steps:

(i) During the loading phase: the temperature variation $\theta(t)$ is always positive during the successive loading phases, and tends to return to zero when the stretch ratio is kept constant. It is worth noting that, if the applied stretch ratio is higher than $\lambda$, the temperature continues to increase for a few seconds before decreasing. This can be seen in Figure 9(a). It is to be noted that the phenomenon is not observed for stretch ratios inferior to $\lambda_{c}$. As thermoelastic coupling cannot explain this phenomenon and as viscosity is not observed in the material under study, the fact that the crystallinity continues is the only explanation for this increase in temperature (crystallization is a strong exothermic phenomenon). It can be noted that similar phenomena have also been observed in metallic materials subjected to first-order phase transformation (accompanied by latent heat production) (Balandraud, Ernst, \& Soos 2000).

ii. During the unloading phase: the temperature variation $\theta(t)$ is always negative during the successive unloading phases, and tends to return

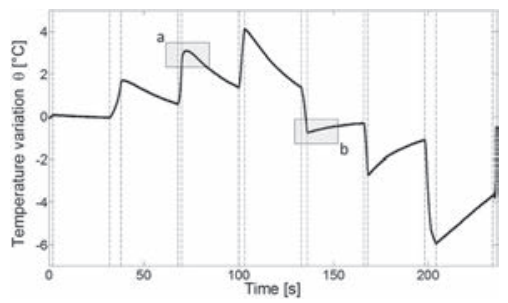

Figure 8. Temperature variation measured during the relaxation test. 


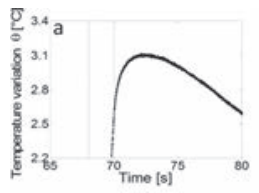

(a) Cyclic test

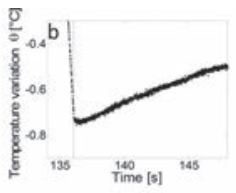

(b) Loading-unloading test with relaxation steps

Figure 9. Magnification of the boxed zones in Figure 8.

to the ambient temperature when the stretch ratio remains constant (see Figure 8). Contrary to loading, no "out-of-phase" phenomenon is observed for pauses at stretch ratios superior to $\lambda_{c}$, as shown in Figure 9(b). This observation confirms the kinetic difference between crystallization and crystallite melting.

\section{CONCLUSION}

This paper investigates the thermal response associated with deformation processes in unfilled natural rubber. For this purpose, cyclic and stress relaxation tests were performed. Temperature variations measured by infrared camera were analyzed during loading, unloading and stress relaxation for the stretch ratio range in which crystallization occurs. Results show that the entropic behaviour of natural rubber leads to heat production (absorption) during loading (unloading). The thermal response is found to provide additional information on deformation processes, more particularly with respect to straininduced crystallization. Indeed, a significant temperature increase is observed when strain-induced crystallization occurs, and the temperature evolution shows that the kinetics of crystallization and of crystallite melting are different. Nevertheless, due to the heat exchange between the specimen and its environment, temperature variation is not the most relevant quantity to link the thermal response to the change in the microstructure. More particularly, temperature variation does not enable us to characterize separately thermomechanical couplings and mechanical dissipation. This is the reason why the calculation of heat sources from the temperature measurement is certainly a new route to revisit the analysis presented in the present paper.

\section{REFERENCES}

Balandraud, X., E. Ernst, \& E. Soos (2000). Relaxation and creep phenomena in shape memory alloys. part ii: Stress relaxation and strain creep during phase transformation. Zeitschrift fur Angewandte Mathematik und Physik 51, 419-448.
Chagnon, G., E. Verron, L. Gornet, G. Marckmann, \& P. Charrier (2004). On the relevance of the Mullins effect as applied to stress-softening in elastomers. Journal of the Mechanics and Physics of Solids 52, 1627-1650.

Chrysochoos, A. \& H. Louche (2000). An infrared image processing to analyse the calorific effects accompanying strain localisation. Int J Eng Sci 38, 1759-1788.

Chrysochoos, A. \& H. Louche (2001). Thermal and dissipative effects accompanying luders band propagation. Mat Sci Eng A-struct 307, 15-22.

Flory, P.J. (1947). Thermodynamics of crystallization in high polymers. i. crystallization induced by stretching. The Journal of Chemical Physics 15, 397-408.

Huneau, B. (2011). Strain-induced crystallization of natural rubber: a review of x-ray diffraction investigations. Rubber Chemistry and Technology 84, 425-452.

Joule, J.P. (1857). On some thermodynamic properties of solids. Phil Mag 4th 14, 227.

Le Cam, J.-B. \& E. Toussaint (2008). Volume variation in stretched natural rubber: competition between cavitation and stress-induced crystallization. Macromolecules 41, 7579-7583.

Marchal, J. (2006). Cristallisation des caoutchoucs chargés et non chargés sous contrainte: Effet sur les chaînes amorphes. Ph. D. thesis, PhD Thesis, Université Paris XI Orsay, France.

Mullins, L. (1948). Effect of stretching on the properties of rubber. Rubber Chemistry and Technology 21, 281-300.

Pottier, T., M.-P. Moutrille, J.-B. LeCam, X. Balandraud, \& M. Grédiac (2009). Study on the use of motion compensation technique to determine heat sources. application to large deformations on cracked rubber specimens. Experimental Mechanics 49, 561-574.

Samaca Martinez, J.R., J.-B. Le Cam, X. Balandraud, E. Toussaint, \& J. Caillard (2013). Mechanisms of deformation in crystallizable natural rubber. part 1 : thermal characterization. Polymer, Doi: 10.1016/j. polymer.2013.03.011.

Stringfellow, R. \& R. Abeyaratne (1989). Cavitation in an elastomer: Comparison of theory with experiment. Materials Science and Engineering: A 112, 127-131.

Toki, S., T. Fujimaki, \& M. Okuyama (2000). Straininduced crystallization of natural rubber as detected real-time by wide-angle $\mathrm{x}$-ray diffraction technique. Polymer 41, 5423-5429.

Toki, S., I. Sics, S. Ran, L. Liu, B. Hsiao, S. Murakami, K. Senoo, \& S. Kohjiya (2002). Macromolecules 35, 6578-6584.

Toussaint, E., X. Balandraud, J.-B. Le Cam, \& M. Grédiac (2012). Combining displacement, strain, temperature and heat source fields to investigate the thermomechanical response of an elastomeric specimen subjected to large deformations. Polymer Testing 31, 916-925.

Trabelsi, S., P.-A. Albouy, \& J. Rault (2002). Stress-induced crystallization around a crack tip in natural rubber. Macromolecules 35, 10054-10061.

Trabelsi, S., P.-A. Albouy, \& J. Rault (2003). Effective local deformation in stretched filled rubber. Macromolecules 36, 9093-9099. 